\title{
Condições higiênico-sanitárias e físico-estruturais da área de manipulação de carne in natura em minimercados de Recife (PE), Brasil
}

\author{
Sanitary-hygienic and physical-structural conditions of meat in natura area of \\ manipulation in the minimarkets of Recife (PE), Brazil
}

\author{
Juliana Nóbrega Pereira da Costa ${ }^{1,2}$, Vládima Virgínia Mendes Santos ${ }^{1,3}$, Giselle Ramos da Silva1, \\ Fernanda Maria Lino de Moura ${ }^{1 *}$, Carlos Alberto Bezerra Gurgel ${ }^{1,4}$, Andrea Paiva Botelho Lapenda de Moura ${ }^{1,5}$
}

RESUMO: De acordo com a Organização Mundial de Saúde, mais de $60 \%$ dos casos de doenças de origem alimentar decorrem do descuido higiênico-sanitário de manipuladores, das técnicas inadequadas de processamento e da deficiência de higiene da estrutura física, de utensílios e equipamentos. Com isso, este estudo objetivou avaliar as condiçóes higiênico-sanitárias e físico-estruturais da área de manipulação de minimercados comercializadores de carnes in natura do Distrito VI de Recife (PE), Brasil. Para isso, foram visitados 21 estabelecimentos, averiguados por meio de um check-list baseado na lista de verificaçáo contida na Resolução de Diretoria Colegiada (RDC) no 275/02 e nas determinaçôes da RDC no 216/2004, ambas do Ministério da Saúde. Os 12 itens do check-list foram divididos em três blocos: Edificaçôes e instalaçôes; Equipamentos, móveis e utensílios; e Higienizaçáo de instalaçóes, equipamentos, móveis e utensílios. Observou-se que $80,95 \%(n=17)$ dos estabelecimentos apresentaram baixo atendimento aos itens avaliados, $19,05 \%(\mathrm{n}=4)$ médio atendimento e nenhum dos minimercados conseguiu um alto atendimento. Faz-se necessário, portanto, melhor acompanhamento pelos funcionários do Serviço de Vigilância Sanitária, promovendo a adequação dos itens não conformes a fim de garantir a oferta de alimentos seguros aos consumidores.

PALAVRAS-CHAVE: alimento; boas práticas de fabricação; legislação; produtos de origem animal; qualidade sanitária.

\begin{abstract}
According to the World Health Organization, more than $60 \%$ of cases of foodborne illnesses result from carelessness hygienic-sanitary handlers, inadequate processing techniques and disability care of the physical structure, fixtures and equipment. Therefore, this study aimed to assess the sanitary conditions and physical-structural manipulation area of minimarkets traders fresh meat of District VI, Recife-(PE), Brazil. For this, 21 establishments were visited, assessed using a checklist based on the checklist contained in Board Resolution no 275/02 and the determinations of Board Resolution no 216/2004, both of the Ministry of Health. The 12 items of the checklist were divided into three blocks: Buildings and facilities; Equipment, furniture and fixtures; and Sanitation facilities, equipments, furniture and fixtures. It was observed that $80.95 \%$ ( $\mathrm{n}=17$ ) of the establishments had low attendance to the items evaluated, $19.05 \%(n=4)$ average attendance and that none of minimarkets got a high attendance. It's necessary, therefore, better monitoring by officials of the Department of Health Surveillance, promoting adequacy of nonconforming items in order to ensure the provision of safe food to consumers.
\end{abstract}

KEYWORDS: food; good manufacturing practices; legislation; animal products; sanitary quality.

\footnotetext{
'Universidade Federal Rural de Pernambuco (UFRPE) - Recife (PE), Brasil.

${ }^{2}$ Vigilância Sanitária e Epidemiológica, Secretaria de Saúde de Vertente do Lério - Vertente do Lério (PE), Brasil.

${ }^{3}$ Vigilância Sanitária do Recife - Recife (PE), Brasil.

${ }^{4}$ Vigilância Sanitária de Ipojuca - Ipojuca (PE), Brasil.

${ }^{5}$ Departamento de Medicina Veterinária da UFRPE - Recife (PE), Brasil.

*Autor correspondente: fernandamary3@gmail.com

Recebido em: 23/03/2012. Aceito em: 19/04/2013
} 


\section{INTRODUÇÃO}

Um alimento seguro deve apresentar suas propriedades nutricionais inerentes, os aspectos sensoriais desejáveis e, do ponto de vista sanitário, ausência ou tolerância de micro-organismos patogênicos e ausência de riscos físicos e químicos (Gomes, 2007).

A qualidade da matéria-prima, a higienização das instalaçóes, dos equipamentos e dos utensílios, as condiçôes higiênicas do ambiente de trabalho, as técnicas de manipulação dos alimentos, a saúde dos funcionários, o controle da água utilizada e os cuidados com os vetores transmissíveis de doenças e pragas são fatores importantes a serem considerados na produção de alimentos de qualidade, devendo, portanto, ser considerados no Programa de Boas Práticas de Fabricação (BPF) (Silva JúNior, 2002; BrasiL, 2004).

Os minimercados são classificados como um comércio varejista de mercadorias em geral, com predominância de produtos alimentícios e área de venda inferior a $300 \mathrm{~m}^{2}$. Oferecem variedade de gêneros alimentícios, bebidas e produtos de limpeza, assim como os supermercados, porém, com estoques e espaço físico reduzidos (Ribeiro; Teixeira, 20го). Por serem comercializadores de alimentos e, muitas vezes, de produtos de origem animal como a carne, adequadas condiçôes de estrutura física, utensílios, móveis e equipamentos são imprescindíveis para garantir a qualidade (Germano; Germano, 2011).

De acordo com a Organização Mundial de Saúde (WHO, 2010), mais de $60 \%$ dos casos de doenças de origem alimentar decorrem do descuido higiênico-sanitário de manipuladores, das técnicas inadequadas de processamento e da deficiência de higiene da estrutura física, utensílios e equipamentos.

Considerando que a contaminação pode ocorrer, em muitos casos, pelas condiçóes insatisfatórias em estabelecimentos que comercializam alimentos, o presente trabalho com base nesta premissa tem como objetivo caracterizar o perfil das condiçôes da área de manipulação de carnes in natura comercializadas em minimercados localizados no Distrito Sanitário VI de Recife (PE), em relação às edificaçôes, instalaçóes, equipamentos, móveis e utensílios.

\section{Visita aos minimercados}

Para a coleta de dados, foram visitados 21 minimercados com comércio de carne in natura nos meses de abril e maio de 2011 nos bairros de Boa Viagem, Brasília Teimosa, Pina, Ipsep, Imbiribeira, Ibura, Jordão e Cohab, que fazem parte do Distrito Sanitário VI, na região político-administrativa 6 (RPA6) da cidade do Recife (PE) (Fig. 1), em companhia dos inspetores sanitários responsáveis pela área.

Foi feito um check-list baseado na lista de verificação contida na Resolução de Diretoria Colegiada (RDC) $n^{\circ} 275 / 02$, nas determinaçóes da RDC no 216/2004, ambas do Ministério da Saúde. Os seus 12 itens foram divididos em 3 blocos: Edificaçôes e instalaçóes; Equipamentos, móveis e utensílios; e Higienização de instalaçôes, equipamentos, móveis e utensílios. A RDC no 275 (Brasil, 2002), embora seja relacionada a estabelecimentos produtores/industrializadores de alimentos, foi utilizada por conter uma base para a classificação de estabelecimentos de acordo com a porcentagem de itens atendidos em uma avaliaçáo realizada por meio de check-list, em alta, média e baixa adequação. Além disso, conta com uma lista de verificação das boas práticas de fabricaçáo para estes estabelecimentos que pode ser adaptada aos que manipulam e comercializam alimento, sem os produzir.

Após a coleta dos dados, os resultados foram tabulados manualmente e armazenados em um banco de dados para serem processados pelo programa Excel 2007. Em seguida, analisou-se, por meio da obtenção da distribuição absoluta e relativa, de acordo com SAMPAIO (2009).

\section{Grupos de minimercados}

Segundo a RDC no 275 (Brasil, 2002), os estabelecimentos podem ser divididos em três grupos de acordo com a porcentagem dos itens atendidos, sendo: Grupo 1 - Alta adequação (76 a 100\% de itens atendidos), Grupo 2 - Média adequação (51 a 75\%) e Grupo 3 - Baixa adequação (0 a 50\%). A partir disso, os minimercados foram classificados em grupos, de acordo com a Tabela 1. Nenhum deles fez parte do Grupo 1 ( $\geq 76 \%$ de atendimento dos itens). No Grupo 2, foram classificados 4 estabelecimentos (19,05\%), atendendo entre 51 e $75 \%$ dos itens avaliados e obtendo média adequaçáo. Já o maior número de estabelecimentos, isto é 17 (80,95\%), apresentou-se no Grupo 3, atendendo entre 51 e $75 \%$ dos itens avaliados e obtendo baixa adequação. Observa-se que o grau de atendimento às BPF em todos os estabelecimentos analisados estava abaixo do preconizado pela Agência Nacional de Vigilância Sanitária (ANVISA), já que é recomendado que os atributos avaliados tenham porcentagens de conformidade maiores que $76 \%$ com o objetivo de minimizar cada vez mais os riscos das toxi-infecçóes alimentares (Brasil, 2002).

No que diz respeito à porcentagem de itens atendidos por bloco, os valores estáo demonstrados na Tabela 2 . Observou-se que o bloco Equipamentos, móveis e utensílios foi o de maior percentual, com $100 \%$ de atendimento aos itens avaliados. O bloco Edificaçôes e instalaçôes apresentou $83,33 \%$ de atendimento, enquanto o de Higienização de equipamentos, móveis e utensílios, 66,66\%. É importante ressaltar que nesta classificação não está representada a quantidade de conformidade e náo conformidade aos itens, o que será demonstrado a seguir, no tocante ao desempenho de cada bloco. 


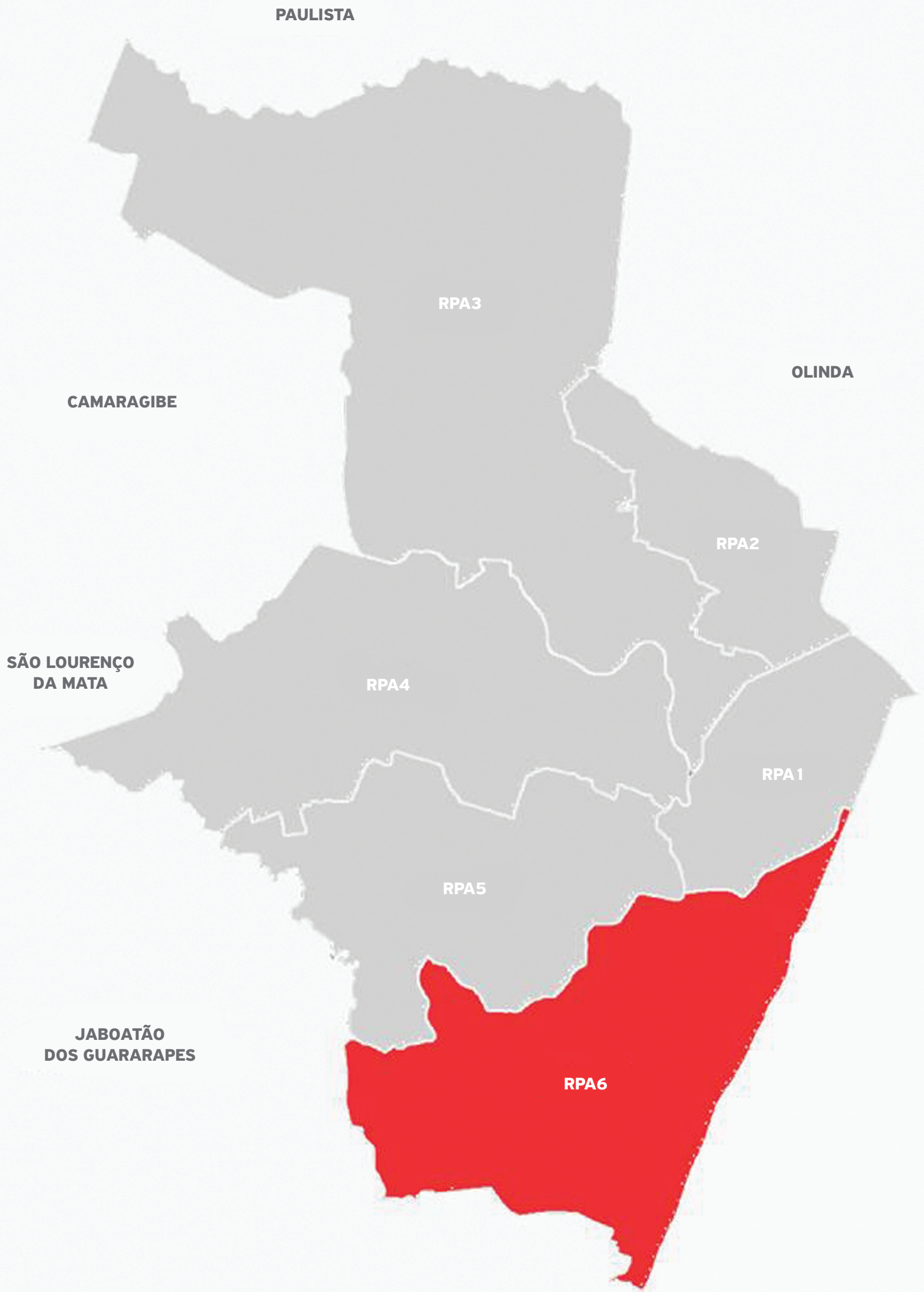

Figura 1. Região político-administrativa 6 da cidade do Recife, Pernambuco, Brasil. 


\section{Edificações e instalações}

No bloco 1, foram avaliadas questóes referentes às edificaçóes e instalaçôes dos estabelecimentos. Neste aspecto, verificou-se em 10 (47,62\%) dos minimercados que itens como piso, parede e teto encontravam-se conservados. Porém, nos outros $11(52,38 \%)$ estabelecimentos havia uma ou mais náo conformidades, tais como: falhas e/ou partes danificadas, infiltraçôes, pisos quebrados, além de cartazes colados nas paredes, o que dificulta a limpeza e higienização. De acordo com a RDC no 216/2004 (BRASIL, 2004), instalaçóes físicas como piso, parede e teto devem possuir revestimento liso, impermeável e lavável. Além disso, precisam ser mantidos íntegros, conservados, livres de rachaduras, trincas, goteiras, vazamentos, infiltraçôes, bolores, descascamentos e outros defeitos que possam veicular contaminantes para os alimentos. Em pesquisa realizada por Miranda; Barreto (2012) em 12 estabelecimentos comercializadores de carne de sol, incluindo 3 minimercados, observou-se que $33,3 \%$ dos minimercados possuía paredes, pisos e bancadas bastante desgastados.

Constatou-se que todos os 21 estabelecimentos estavam providos de pontos com água corrente, sendo que em $18(85,71 \%)$ esta água era proveniente da Companhia Pernambucana de Saneamento (COMPESA). Já os $3(14,28 \%)$ minimercados utilizavam água proveniente de poços artesianos, sem laudos laboratoriais de exames físico-químicos e/ou microbiológicos. A água usada nos estabelecimentos que comercializam alimentos pode ser fonte de micro-organismos se não houver controle microbiológico e não forem dispensados os cuidados necessários com o seu abastecimento (AmARAL et al., 2007). Neste sentido, a RDC $\mathrm{n}^{\circ}$ 216/2004 (BrAsIL, 2004) preconiza que as instalaçôes devem ser abastecidas com pontos de água corrente, devendo-se,

Tabela 1. Quantidade e Classificação dos minimercados avaliados no Distrito Sanitário VI, Recife (PE), Brasil, de acordo com o percentual de itens atendidos, segundo a Resolução de Diretoria Colegiada n 275 (BRASIL, 2002).

\begin{tabular}{lc}
$\begin{array}{l}\text { Classificação dos minimercados } \\
\text { e \% de itens atendidos }\end{array}$ & Estabelecimentos - $\mathbf{n}(\%)$ \\
\hline Grupo $1(\geq 76 \%)$ & $0(0)$ \\
\hline Grupo $2(51$ a $75 \%)$ & $4(19,05)$ \\
\hline Grupo $3(\leq 50 \%)$ & $17(80,95)$ \\
\hline TOTAL & $21(100,00)$ \\
\hline
\end{tabular}

Tabela 2. Porcentagem de itens atendidos por bloco segundo a Resolução de Diretoria Colegiada nº 275 (BRASIL, 2002).

\begin{tabular}{lc} 
Blocos & Itens atendidos (\%) \\
\hline Edificações e instalações & 83,33 \\
\hline Equipamentos, móveis e utensílios & 100,00 \\
\hline $\begin{array}{l}\text { Higienização de equipamentos, } \\
\text { móveis e utensílios }\end{array}$ & 66,66 \\
\hline
\end{tabular}

para isso, usar água potável nos procedimentos de manipulaçáo de alimentos. Caso seja utilizada uma solução alternativa de abastecimento, a potabilidade da água deve ser atestada semestralmente por meio de laudos laboratoriais.

Quanto à variável fluxo de ar (natural ou mecânico), percebeu-se que em todos os estabelecimentos este incidia sobre os alimentos, e que não havia barreira física na área de manipulação para evitar a entrada do ar proveniente de outras áreas. Segundo o Decreto Estadual no 20.786 (Pernambuco, 1998), a direção da corrente de ar não deve ser da área suja para a área limpa e, de acordo com a RDC no 216/2004 (BRASIL, 2004), a ventilaçáo deve garantir a renovação do ar e a manutenção do ambiente livre de fungos, gases, fumaça, pós, partículas em suspensão, condensação de vapores, dentre outros, e o fluxo de ar náo deve incidir sobre o alimento para náo comprometer a sua qualidade higiênico-sanitária.

No que diz respeito às instalações sanitárias, verificou-se que em $5(23,81 \%)$ minimercados elas estavam bem conservadas, ao contrário dos outros $16(76,19 \%)$ estabelecimentos visitados. Em apenas 1 (4,76\%) observou-se comunicação com a área de manipulaçáo e armazenamento das carnes comercializadas. Além disso, constatou-se também que em $20(95,24 \%)$ estavam disponíveis sabão líquido inodoro e toalhas de papel para higienização das mãos dos funcionários. Sobre isso, Mürmann et al. (2004) relataram que mais da metade $(52,5 \%)$ dos estabelecimentos que comercializam alimentos na cidade de Santa Maria (RS) apresentaram inadequaçôes nas instalaçôes sanitárias. Conforme a RDC no 216/2004 (Brasil, 2004), as instalaçóes sanitárias e os vestiários não devem ter comunicação com a área de manipulaçáo e armazenamento dos alimentos, que devem ser mantidos organizados e conservados, e as instalaçóes sanitárias devem possuir lavatórios e estar supridas de produtos destinados à higiene pessoal, tais como papel higiênico, sabão líquido inodoro, produto antisséptico e toalhas de papel não reciclado, ou outro sistema higiênico e seguro, para secagem das mãos.

\section{Equipamentos, móveis e utensílios}

No bloco 2 foram avaliados itens relacionados aos equipamentos, móveis e utensílios. Assim, no tocante aos coletores de resíduos, observou-se que em $9(42,86 \%)$ minimercados estavam dotados de sacos plásticos no seu interior e eram de acionamento por pedal, evitando aglomeração de pragas, ao contrário de outros $12(57,14 \%)$ estabelecimentos, nos quais foi observada a existência de lixeiras sem sacos plásticos, pedal e/ou tampa ou, ainda, com a tampa quebrada. De acordo com a RDC no 216/2004, os coletores de resíduos devem ser dotados de tampa e acionados sem contato manual.

Sobre a existência de lavatórios exclusivos para higiene das mãos, $4(19,04 \%)$ estabelecimentos estavam de acordo com a legislação, possuindo lavatório exclusivo, com sabão 
líquido inodoro, antisséptico, toalhas de papel e lixeiras com saco plástico e tampa acionada por pedal. Porém foram pontuados $17(80,95 \%)$ estabelecimentos que náo possuíam lavatórios e, ainda, nos quais os funcionários utilizavam pias destinadas à lavagem de utensílios. De acordo com a RDC 216/2004 (Brasil, 2004), os estabelecimentos devem disponibilizar lavatórios exclusivos para a higiene das máos na área de manipulaçáo, em posiçóes estratégicas em relaçáo ao fluxo de preparo dos alimentos e em número suficiente, de modo a atender toda a área de preparação. Os lavatórios devem contar com sabão líquido inodoro, antisséptico, toalhas de papel não reciclado ou outro sistema higiênico e seguro de secagem das mãos e coletor de papel acionado sem contato manual. Além disso, os manipuladores devem lavar cuidadosamente as mãos ao chegar ao trabalho, antes e após manipular alimentos, depois de qualquer interrupçáo do serviço, de tocar materiais contaminados ou usar os sanitários e sempre que se fizer necessário. Souza (2006) comenta que as mãos constituem importante foco de micro-organismos. Assim, quando mal higienizadas, podem veicular micro-organismos que são transferidos para os alimentos.

Diante disso, alguns aspectos devem ser observados e controlados para que os manipuladores não constituam uma fonte de contaminação alimentar, entre eles o controle de saúde, grau de instrução, hábitos de higiene pessoal e utilização de procedimentos operacionais padronizados e de boas práticas de fabricação.

Em relação às superfícies de equipamentos, móveis e utensílios usados na manipulação das carnes, em 16 (76,19\%) minimercados constatou-se superfícies lisas, impermeáveis e laváveis, e em 5 (23,81\%) observou-se superfícies de madeira, elemento que não deve ser utilizado por ser de difícil higienização, facilitando a proliferação de micro-organismos.

De acordo com o Decreto Estadual no 20.786 (Pernambuco, 1998), todo o equipamento e os utensílios utilizados nos locais de manipulação de alimentos e que possam entrar em contato com o alimento devem ser confeccionados com material que não transmita substâncias tóxicas, odores e sabores, ser não absorventes e resistentes à corrosão e capaz de resistir a repetidas operaçôes de limpeza e desinfecção. Além disso, superfícies precisam ser lisas e sem frestas e outras imperfeiçôes que se transformem em fonte de contaminação.

A esse respeito, a RDC no 216 (BrasiL, 2004) estabelece que os instrumentos de manipulação devem ser mantidos em adequado estado de conservação, já que a má condição de preservação dos utensílios pode proporcionar a formação de rachaduras, o que dificulta a higienização e promove a formação de biofilmes, favorecendo a contaminação dos alimentos. Neste contexto, Guimaráes; Figueiredo (2010) comentam que os utensílios utilizados precisam ser armazenados em local apropriado, de forma organizada e protegidos de qualquer fonte de contaminação. Em estudo semelhante, VALEjO et al. (2003), quando vistoriaram 52 serviços de alimentação na cidade de Presidente Prudente (SP), constataram que os maiores problemas foram em relação à má conservação de utensílios e equipamentos.

\section{Higienização de instalações, móveis e utensílios}

No bloco 3 foram avaliadas questôes sobre a higienização de instalaçôes, equipamentos, móveis e utensílios. No que se refere à higienização, verificou-se que em 3 (14,28\%) estabelecimentos as instalaçôes estavam visualmente limpas e em $18(85,71 \%)$ observou-se sujidades e sangue proveniente de carnes. Neste contexto, Sото et al. (2006), pesquisando as condiçóes sanitárias de quatro supermercados do município de Ibiúna (SP), verificaram que os procedimentos de limpeza e desinfecçâo do local eram feitos de forma inadequada. Em relaçâo aos equipamentos, móveis e utensílios, verificou-se que em 5 (23,8\%) minimercados estes itens estavam em condiçóes adequadas de higiene e que em $16(76,19 \%)$ as condições estavam não conformes, sendo observados restos de carnes e sangue nos utensílios.

De acordo com Новвs е Roberts (1999), os equipamentos e utensílios podem ser responsáveis por contaminações cruzadas, devendo ser de fácil limpeza e desinfecção, facilmente desmontáveis e montáveis. Da mesma forma, falhas nos procedimentos de higienização e sanitização permitem aderência de resíduos em equipamentos e utensílios, que se transformam em fonte de contaminação (CHESCA et al., 2003). A RDC no 216/2004 (Brasil, 2004) preconiza que as instalaçōes, os equipamentos, móveis e utensílios devem ser mantidos em condições higiênico-sanitárias apropriadas e as operações de higienização e sanitização realizadas com frequência e por funcionários comprovadamente capacitados, garantindo a manutenção dessas condiçóes e minimizando o risco de contaminação ao alimento.

Com relação aos achados caracterizados como não conformes explicitados na presente pesquisa, considera-se preocupante, uma vez que podem favorecer a contaminação dos alimentos que permanecem em contato com estes equipamentos e utensílios mal higienizados, ou mesmo constituídos de material de difícil higienizaçấo.

No que diz respeito ao armazenamento dos produtos saneantes, utensílios e equipamentos utilizados na higienização, observou-se que todos os 21 estabelecimentos estudados estavam não conformes, sendo encontrados produtos em locais inapropriados. A não separação entre os utilizados na limpeza e higienização e os alimentícios pode contribuir para a contaminação química nos alimentos, bem como a absorção de odores, levando à sua condenação. De acordo com a RDC $n^{\circ} 216 / 2004$, os produtos saneantes devem ser identificados e guardados em local reservado para esta finalidade (BrASIL, 2004). A este respeito, a Norma Técnica Especial (NTE) 01/95 (RECIFE, 1995) diz que o alimento e a matéria-prima in natura 
devem ser protegidos de contaminação animal, elementos químicos ou microbiológicos ou por outras substâncias indesejáveis durante manipulação e armazenamento. CASTRO et al. (2006), em visitas a estabelecimentos self-service em shoppings do Rio de Janeiro, constataram diversas irregularidades com relaçâo às condiçôes higiênico-sanitárias e o não atendimento às legislaçôes vigentes em $100 \%(n=9)$ dos estabelecimentos verificados.

A partir do exposto, conclui-se que as condiçóes higiênico-sanitárias e físico-estruturais de edificaçôes, instalaçôes, equipamentos, móveis e utensílios utilizados nos estabelecimentos visitados são insatisfatórias em alguns casos, não atendendo aos dispositivos preconizados nas legislaçôes em vigor e favorecendo um grande risco ao consumidor. Faz-se necessário, portanto, melhor acompanhamento pelos funcionários do Serviço de Vigilância Sanitária, promovendo a adequaçáo dos itens não conformes a fim de garantir a oferta de alimentos seguros aos consumidores.

Os autores agradecem aos inspetores responsáveis pela inspeção sanitária nos estabelecimentos do Distrito Sanitário VI e aos responsáveis pelos minimercados pela permissão do acompanhamento nas visitas e coleta de dados.

\section{REFERÊNCIAS}

AMARAL, L.A.; ROSSI JÚNIOR, O.D.; NADER FILHO, A.; FERREIRA, F.L.A.; HAGI, D.D. Água utilizada em estabelecimentos que comercializam produtos cárneos, na cidade de Jaboticabal/SP, como via de contaminação dos alimentos. Revista Brasileira de Ciência Veterinária, Rio de Janeiro, v. 14, n. 1, p. 3-6, 2007.

BRASIL. Ministério da Saúde. Resolução RDC n²16, de 15 de setembro de 2004. Aprova o regulamento técnico de boas práticas para serviços de alimentação. Diário Oficial da União, Brasília, 2004.

Ministério da Saúde. Resolução RDC n²75, de 21 de outubro de 2002. Dispõe sobre o regulamento técnico de procedimentos operacionais padronizados aplicados aos estabelecimentos produtores/industrializadores de alimentos e a lista de verificação das boas práticas de fabricação em estabelecimentos produtores/industrializadores de alimentos. Diário Oficial da União, Brasília, 2002.

CASTRO, F.T.; TABAI, K.C.; BARBOSA, C.G.; DORNA, N.S. Restaurantes self-services: situação higiênico-sanitária dos shoppings do município do Rio de Janeiro. Revista da Universidade Federal Rural do Rio de Janeiro, Rio de Janeiro, v.26, n.2, p.87-101, 2006.

CHESCA, A.C.; MOREIRA, P.A.; ANDRADE, S.C.B.J.; MARTINELLI, T.M. Equipamentos e utensílios de unidades de alimentação e nutrição: um risco constante de contaminação das refeições. Revista Higiene Alimentar, São Paulo, v.17, n. $114 / 115$, p. 20-23, 2003.

GERMANO, P.M.L; GERMANO, M.I.S. Higiene e vigilância sanitária de alimentos. São Paulo: Manole, 2011. 1034p.

GOMES, J.C. Legislação de alimentos e bebidas. Viçosa: UFV, 2007.635p.

GUIMARÃES, S.L.; FIGUEIREDO, E.L. Avaliação das condições higiênico-sanitárias de panificadoras localizadas no município de Santa Maria do Pará-PA. Revista Brasileira de Tecnologia Agroindustrial, Paraná, v.4, n.2, p. 198-206, 2010.
HOBBS, B.C.; ROBERTS, D. Toxinfecções e controle higiênicosanitário de alimentos. São Paulo: Varela, 1999. 376p.

MIRANDA, P.C.; BARRETO, N.S.E. Avaliação higiênico-sanitária de diferentes estabelecimentos de comercialização da carnede-sol no município de Cruz das Almas-BA. Revista Caatinga, Mossoró, v. 25, n. 2, p. 166-172, 2012.

MÜRMANN, L.; FICK, F.A.; DILKIN, M.; ARAUJO, D.; DILKIN, P.; MALLMANN, C. A. Condições higiênicas dos sanitários dos estabelecimentos alimentícios localizados na cidade de Santa Maria/RS. In: CONGRESSO ESTADUAL DA MEDICINA VETERINÁRIA, 16.,CONGRESSO DE MEDICINA VETERINÁRIA DO CONESUL, 5., 2004, Rio Grande do Sul. Resumos.

PERNAMBUCO. Governo do Estado. Secretaria de Saúde de Pernambuco. Decreto n²0.786, de 10 de agosto de 1998. Regulamenta o código sanitário do Estado de Pernambuco. Diário Oficial do Estado, Pernambuco, 1998.

RECIFE. Prefeitura da Cidade. Secretaria de Saúde do Recife. Portaria n 49/95, de 24 de outubro de 1995. Dispõe sobre normas técnicas em alimentos - NTE 01/95. Diário Oficial do Município do Recife, Recife, 1995.

RIBEIRO, M.C.A.; TEIXEIRA, N.L.B. Primeiro passo: planejamento empresarial - minimercado. Rio de Janeiro: SEBRAE, 2010. 40p.

SAMPAIO, C.R.P. Desenvolvimento e estudo das características sensoriais e nutricionais de barras de cereais fortificadas com ferro. 2009. 87p. Dissertação (Mestrado - Tecnologia de Alimentos) - Universidade Federal do Paraná, Curitiba, 2009. Disponível em: <http://www.posalim.ufpr.br/Pesquisa/pdf/ DissertaCamilaS.pdf >. Acesso em: 25 jul. 2011.

SILVA JÚNIOR, E.A. Manual de controle higiênico-sanitário em alimentos. São Paulo: Varela, 2002. 475p.

SOTO, F.R.M.; RISSETO, M.R.; CAZZOLA, C.P.B.; ALVES, L.C.R.; BALIAN, S.C.; MALDONADO, A.G.; PINHEIRO, S.R.; TELLES, E.O. 
Proposta e análise crítica de um protocolo de inspeção e de condições sanitárias em supermercados do município de Ibiúna SP. Revista Brasileira de Epidemiologia, São Paulo, v.9, n.2, p.235241, 2006.

SOUZA, L.H.L. A manipulação inadequada dos alimentos: fator de contaminação. Revista Higiene Alimentar. São Paulo, v.20, n. 146, p.32-39, 2006.
VALEJO, F.A.M.; ANDRÉS, C.R.; MANTOVAN, F.B.; RISTER, G.P.; SANTOS, G.D.; ANDRADE, F.F. Vigilância sanitária: avaliação e controle de qualidade dos alimentos. Revista Higiene Alimentar, São Paulo, v.17, n.106, p.16-21, 2003.

WHO. World Health Organization. Foodborne disease. Disponível em: <http://www.who.int/topics/foodborne_diseases/en/>. Acesso em: 3 jun. 2010. 